\title{
Variable sex chromatin pattern in an early carcinoma of the bladder
}

\author{
N. B. ATKIN AND I. PETKOVIĆ \\ From the Department of Cancer Research, Mount Vernon Hospital, Northwood, Middlesex
}

SYNOPSIS Sex chromatin studies on squash preparations of a well differentiated transitional cell carcinoma of the bladder without evidence of invasion from a female aged 63 revealed a single body in some regions, but two to four bodies in others. All regions were near diploid according to DNA estimations. Previous observations on a variety of invasive tumours of females showed that the presence of more than one sex chromatin body is generally associated with a high chromosome number. The pattern of two or more bodies in near-diploid cells seen in this non-invasive tumour may therefore characterize an intermediate stage of clonal evolution, eventually resulting in malignancy, when the cell line has not yet achieved the ability to invade or metastasize.

Sex chromatin presents an anomalous pattern in a substantial minority of malignant tumours of females; in a study of 732 tumours, while a single body was seen in $58 \%$, sex chromatin was absent in $31 \%$, duplicated in $10 \%$, and triplicated in $0.6 \%$ (Atkin, 1967). Within most tumours a consistent pattern was seen. In the present tumour, an unusually varied pattern was found, one to four bodies being present in different regions. This pattern is possibly related to the early stage of the tumour.

\section{Case Report}

A woman, aged 63 , was admitted for investigation following recent haematuria. On cystoscopy a papillary tumour seen near the orifice of the right ureter was removed by diathermy. Histological examination (Dr M. H. Bennett) showed a superficial papillary, well differentiated grade I transitional cell carcinoma; no evidence of invasion was seen (Fig. 1). Fourteen months after the diathermy the patient remained well and cystoscopy showed no abnormality.

\section{Cytogenetic Studies}

Aceto-orcein squash preparations were made from small portions of tumour tissue after fixation in $1: 3$ acetic alcohol. Further pieces of tumour were fixed by freeze-substitution for estimation of Feulgen-DNA content (Atkin and Richards, 1956). Received for publication 10 November 1972.
A leucocyte culture was prepared for chromosome studies. Buccal smears for sex chromatin evaluatio were fixed in $95 \%$ alcohol and stained in aceto orcein.

In the assessment of sex chromatin in the tumou cells, and particularly in distinguishing multiple sex chromatin bodies from multiple non-specific chromocentres, account was taken of the distinguishing features of sex chromatin which have previously been described (Atkin, 1967).

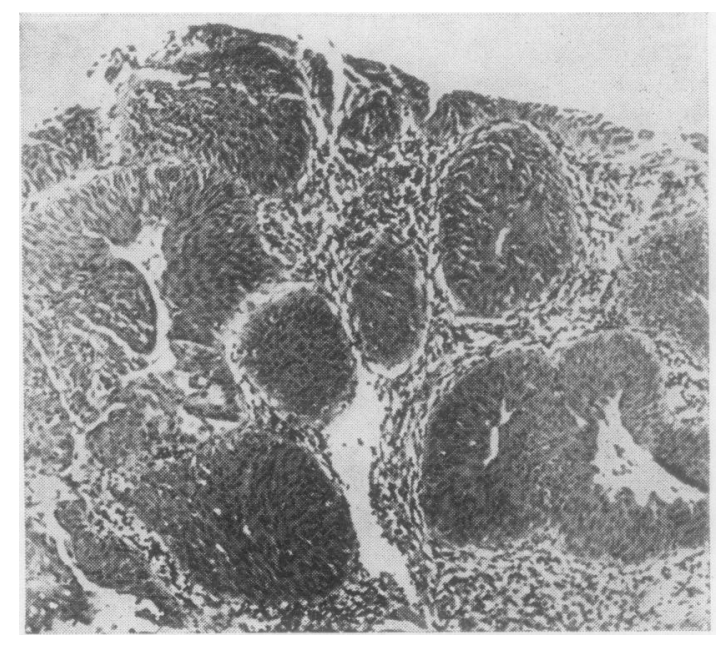

Fig. 1 Histological section of the tumour. $H \& E . \times 63$. 


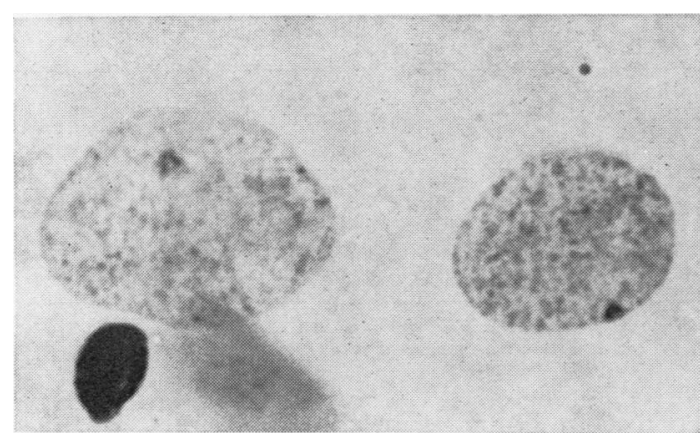

Fig. 2

Figs. 2-4 Sex chromatin in aceto-orcein squash preparations of tumour tissue.

Fig. 2 Single body. The nucleus on the left shows the $U$-shaped form typical of sex chromatin in this type of preparation. $\times 1900$.

Fig. 3 Junction of two tumour regions: at the top, one or two bodies; below, mainly three or four bodies. $\times 500$.

Fig. 4 Two to four bodies. $a \times 488 ; b \times 1472$.

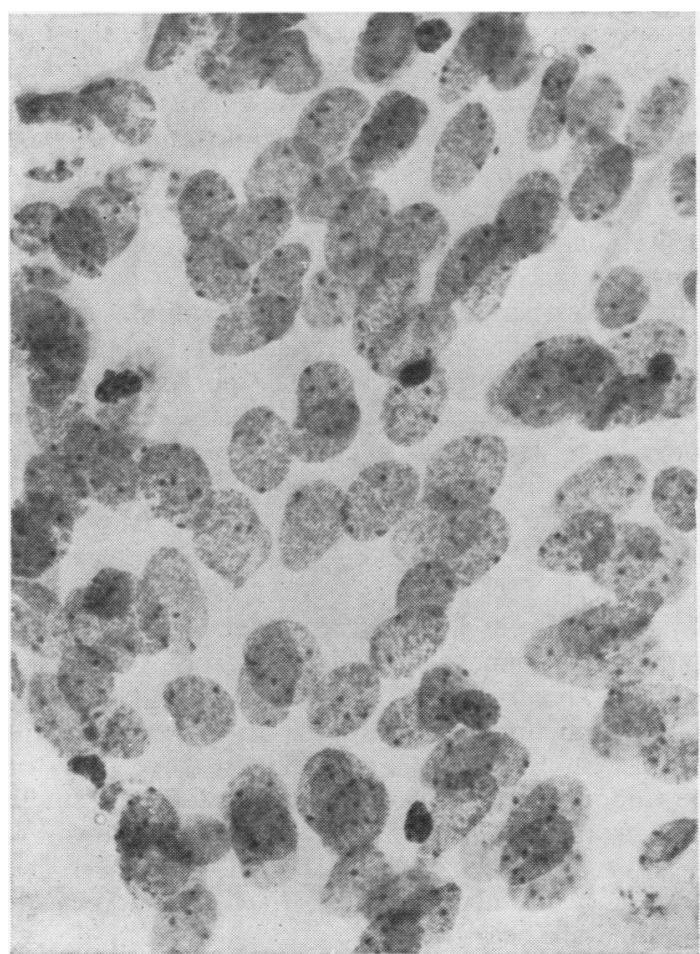

Fig. 4a

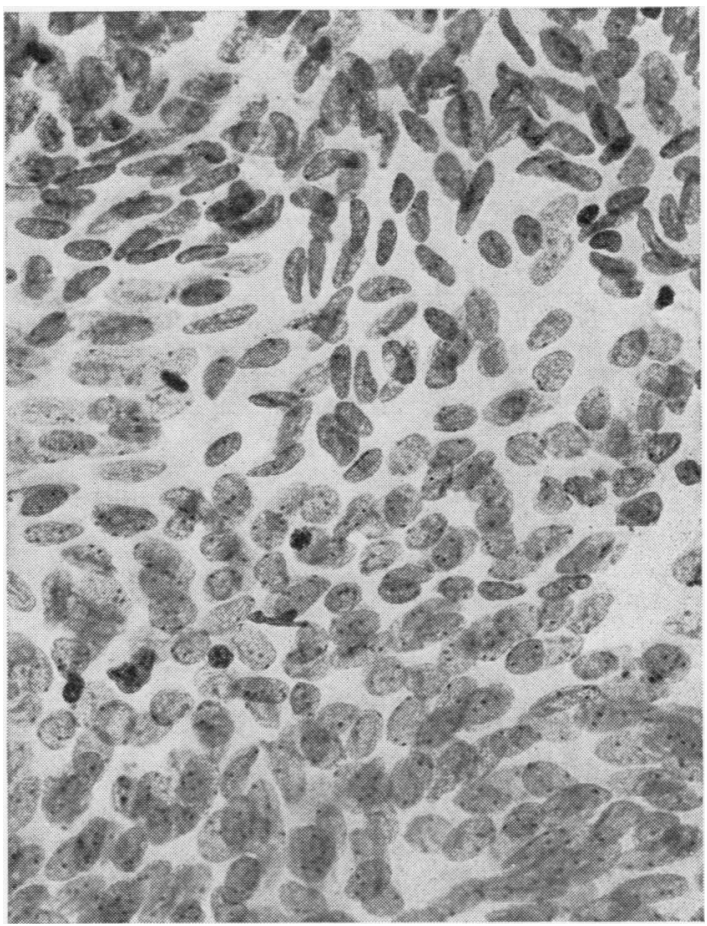

Fig. 3

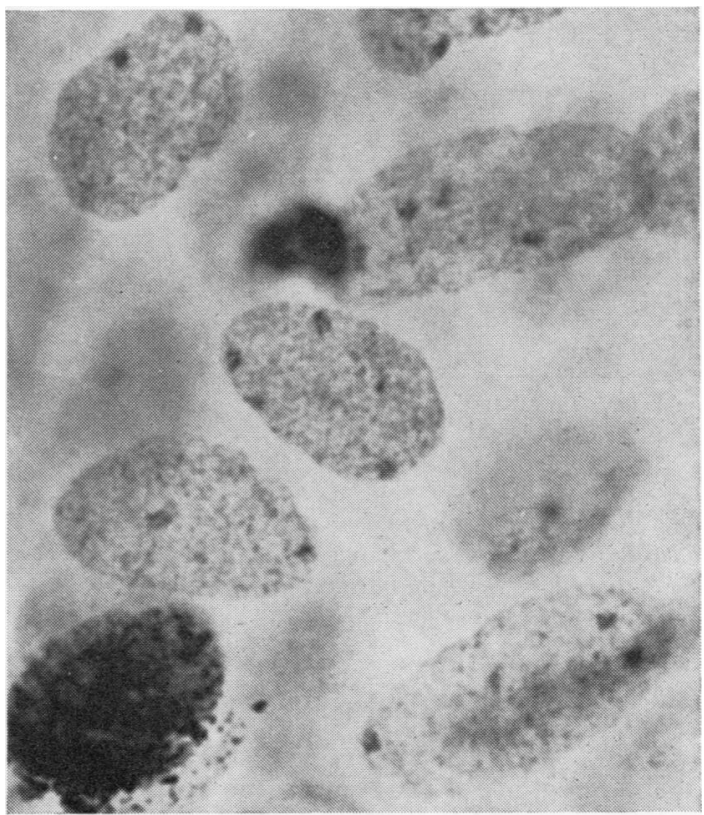

Fig. 4b 


\begin{tabular}{|c|c|c|c|c|c|c|c|}
\hline \multirow[t]{3}{*}{ Region } & \multicolumn{7}{|c|}{ Number of Cells } \\
\hline & \multicolumn{5}{|c|}{ Number of Sex Chromatin Bodies } & \multirow[t]{2}{*}{ Not Assessed } & \multirow[t]{2}{*}{ Total } \\
\hline & 0 & 1 & 2 & 3 & 4 & & \\
\hline With uniform pattern & $\begin{array}{c}6 \\
(3 \%)\end{array}$ & $\begin{array}{l}167 \\
(82 \%)\end{array}$ & $\begin{array}{c}26 \\
(13 \%)\end{array}$ & $\begin{array}{c}3 \\
(1.5 \%)\end{array}$ & 0 & $\begin{array}{l}2 \\
(1 \%)\end{array}$ & 204 \\
\hline With variable pattern & 0 & $\begin{array}{l}103 \\
(20 \%)\end{array}$ & $\begin{array}{l}154 \\
(30 \%)\end{array}$ & $\begin{array}{l}155 \\
(30 \%)\end{array}$ & $\begin{array}{l}91 \\
(18 \%)\end{array}$ & $\begin{array}{l}7 \\
(1.4 \%)\end{array}$ & 510 \\
\hline
\end{tabular}

Table Incidence of sex chromatin in tumour cells (aceto-orcein squash preparations)

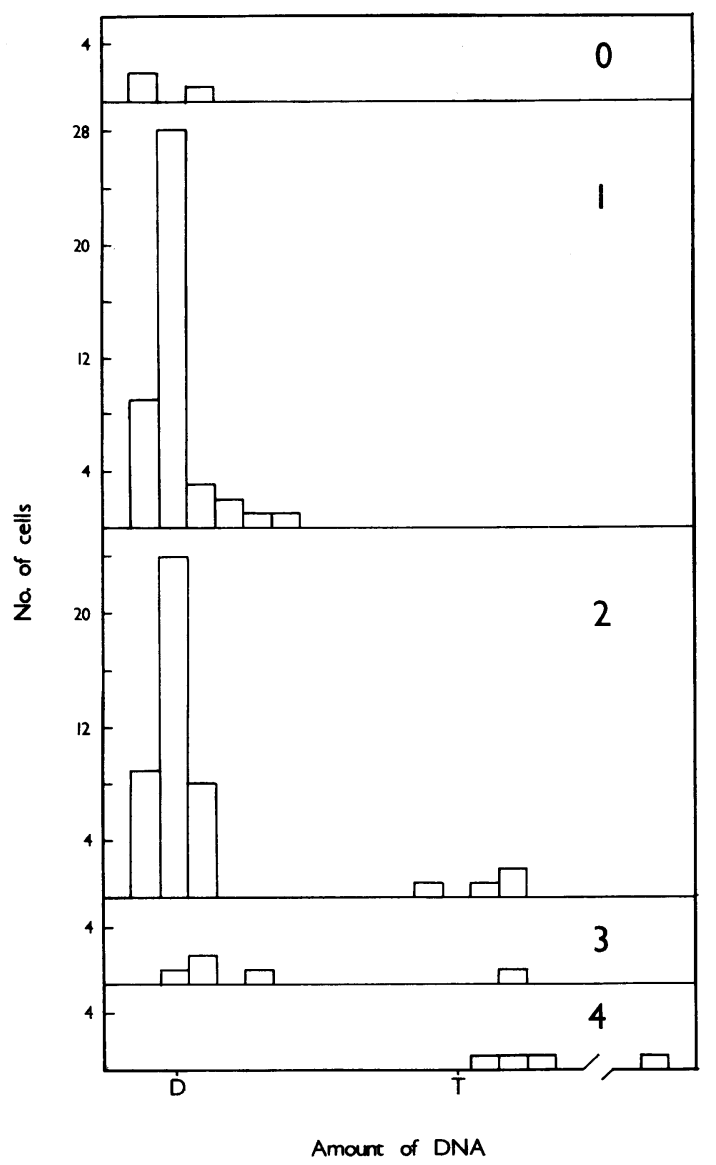

Fig. 5 DNA values of interphase tumour cells according to the number of sex chromatin bodies (indicated by the figures on the right). $D$ and $T=$ diploid and tetraploid levels respectively.

\section{Results}

In some regions of the tumour the cells were small and regular, and a single sex chromatin body was seen in a high proportion. In other regions, however, two to four bodies were commonly present (Figs. 2-4 and table).

Measurements of DNA on Feulgen-stained smears of tumour cells showed that most of the cells with one, two, and three bodies were near diploid (Fig. 5). Although the few cells with four bodies that were measured had near-tetraploid DNA contents, it seems quite likely from their size and intensity of staining in the orcein-stained preparations that some of the cells with four bodies were also near diploid (Fig. 4).

Sex chromatin was present in 40 out of 120 cells in buccal smears; no cells with more than one body were seen.

Karotype studies on a leucocyte culture showe no abnormality. Of 60 cells counted, 51 had $4 \bar{Q}$ chromosomes and nine had less than 46 . Thirty-ones. cells with 46 chromosomes were karyotyped and showed a normal female complement; four cells with 45 and one with 43 chromosomes showed random chromosome loss.

Although pieces of tumour tissue were prepared for karyotype studies, mitoses were very scanty and no well spread metaphases were found.

Of 22 further transitional cell carcinomas of the bladder in female patients studied in this laboratory, all showed a more or less consistent pattern with 0 , one, two or, in one tumour, three, sex chromatin bodies. The latter was a grade 3 tumour having a hypotetraploid modal DNA value.

\section{Comment}

As is common in well differentiated tumours of the bladder, the nuclei were remarkably free from 0 multiple chromocentres, and consequently a very $N$ high proportion were suitable for sex chromatin 어 assessment. It was apparent that in some parts of $\widetilde{\sigma}$ the tumour the majority of cells contained a single sex chromatin body. In other regions, however, two to four bodies were present in most cells. The DNA measurements showed that both types of tumour were near diploid.

It is suggested that the tumour was in the process of chromosomal evolution, a manifestation of the 
change being an increase in the number of sex chromatin bodies. This increase was presumably achieved by nondisjunction of the inactive $X$ chromosome, since polyploidization had not taken place. The near-diploid constitution of the cells with two or three sex chromatin bodies is remarkable in view of the observation that malignant tumours characterized by two or three sex chromatin bodies almost invariably have a chromosome number in the hypertriploid or tetraploid range (Atkin, 1960, 1967).

On histological examination, the tumour showed no signs of invasion. It may therefore represent an earlier stage than is commonly encountered in malignant tumours. At this early stage there may be a multiplicity of clones rather than the single clone commonly found in invasive tumours (Atkin, 1970, 1972); in this respect, the condition might be analogous to dysplasia and carcinoma in situ in the cervix uteri where evidence for the presence in some lesions of more than one clone has been obtained from DNA data (Atkin, 1969). The cells with a single sex chromatin body in the areas with a regular pattern may have diploid chromosome complements, as have been described in some well and moderately differentiated bladder carcinomas (Spooner and Cooper, 1972). Alternatively, they might show a small chromosome change such as the single trisomy found in early carcinomas of the corpus uteri (Baker, 1968).

The regions with more than one sex chromatin body present an unusual pattern which perhaps represents a further stage in the direction of malignancy. However, since the pattern of neardiploid cells with two or more sex chromatin bodies is unlike any commonly encountered in tumours of, for instance, the cervix uteri, breast, and large bowel whose malignancy is not in doubt, it may represent a stage which is still short of malignancy; some further chromosome change may have to occur before the cell line has the capacity to invade. This is, of course, speculative, but perhaps further studies will reveal other near-diploid tumours with this pattern of variable sex chromatin. Since the relevant observations can be made on interphase cells, they are not dependent on possibly unsuccessful techniques for the spreading of tumour metaphase chromosomes.

We thank Mr I. H. Griffiths, FRCS, for kindly providing the material for this study, which was supported by a grant from the Cancer Research Campaign.

\section{References}

Atkin, N. B. (1960). Sex chromatin and chromosomal variation in human tumours. Acta Un. int. Cancr., 16, 41-46.

Atkin, N. B. (1967). Triple sex chromatin, and other sex chromatin anomalies, in tumours of females. Brit. J. Cancer, 21, 40-47.

Atkin, N. B. (1969). The use of microspectrophotometry. (Conference on early cervical neoplasia.) Obstet. Gynec. Surv., 24, 793-804.

Atkin, N. B. (1970). Cytogenetic studies on human tumors and premalignant lesions: the emergence of aneuploid cell lines and their relationship to the process of malignant transformation in man. In Genetic Concepts and Neoplasia, edited by $\mathbf{R}$. W. Cumley. Proceedings of the 23rd Annual Symposium on Fundamental Cancer Research, 1969, University of Texas, M. D. Anderson Hospital and Tumor Institute, Houston, pp. 36-56. Williams and Wilkins, Baltimore.

Atkin, N. B. (1972). Chromosomes in human tumors: an assessment and review. In Chromosomes and Cancer, edited by J. German. J. Wiley, New York (In press).

Atkin, N. B., and Richards B. M. (1956). Deoxyribonucleic acid in human tumours as measured by microspectrophotometry of Feulgen stain: a comparison of tumours arising at different sites. Brit. J. Cancer., 10, 769-786.

Baker, M. C. (1968). A chromosome study of seven near-diploid carcinomas of the corpus uteri. Brit. J. Cancer, 22, 683-695.

Spooner, M. E., and Cooper, E. H. (1972). Chromosome constitution of transitional cell carcinoma of the urinary bladder. Cancer (Philad). 29, 1401-1412. 